\title{
FOUR QUESTIONS OF ITERATED GROUNDING
}

\author{
[forthcoming in Philosophy and Phenomenological Research. \\ Draft; please cite the final version]
}

\begin{abstract}
The Question of Iterated Grounding (QIG) asks what grounds the grounding facts. Although the question received a lot of attention in the past few years, it is usually discussed independently of another important issue: the connection between metaphysical explanation and the relation or relations that supposedly "back" it. I will show that once we get clear on the distinction between metaphysical explanation and the relation(s) backing it, we can distinguish no fewer than four questions lumped under QIG. I will also argue that given some plausible assumptions about what it would take for a relation to back metaphysical explanation, many salient views about grounding allow us to give "easy" answers to these questions-easy in the sense that we can straightforwardly derive them from the respective conception of grounding without getting into the sorts of complexities that typically inform answers to QIG. The paper's main upshot is that we cannot expect to make much progress on QIG without first addressing the difficult issue of how exactly grounding is related to metaphysical explanation.
\end{abstract}

\section{Introduction}

Much has been written lately about grounding, a relation that is thought to have a distinctively metaphysical explanatory import. ${ }^{1}$ For example mental facts might be grounded in physical facts, moral facts in natural facts, facts about wholes in the properties and relations among their parts, and so on. In lines with much of the literature, I will express grounding using a sentential connective, ' $<$, whose behavior is similar to that of the natural language expression 'because' except that it takes a sentence on the right side (the "grounded" side) and a plurality of sentences on the left side (the "grounding" side). Thus, a grounding statement will take the following form:

$$
A_{1} \ldots A_{n}<B^{2}
$$

\footnotetext{
${ }^{1}$ Contemporary classics that define the direction of much of the contemporary literature include Fine 2001, 2012, Correia 2005: Ch. 3, Schaffer 2009, and Rosen 2010.

${ }^{2}$ See Fine 2001, 2012, deRosset 2013, Dasgupta 2014b and Litland 2017 for similar treatments. Dasgupta (2014a) conceives of grounding as irreducibly many-many, rather than one-many; unfortunately, in the present paper I cannot discuss this interesting proposal.
} 
There are other ways of expressing grounding (a familiar one is to express it as many-one relation between facts) ${ }^{3}$, but in what follows I will stick to the connective approach partly out of convenience and partly in order to avoid difficult but largely tangential questions about the metaphysics of facts. As far as I can see, the choice between relational and connective formulations will make little difference to the rest of the paper. For stylistic reasons I will often informally speak of a relation of grounding that holds between the facts that $A_{1} \ldots A_{n}$ and the fact that $B$, but this should always be read as elliptical for simply saying that $A_{1} \ldots A_{n}<B$. My main focus throughout the paper will be on full grounding $\left(A_{1} \ldots A_{n}\right.$ fully ground $B$ when they are non-redundantly sufficient on their own to ground B) rather than partial grounding (which holds between any proper sub-plurality of B's full grounds and B itself). ${ }^{4}$ Moreover, I will work with a factive notion of grounding, i.e. I will assume that if $A_{1} \ldots A_{n}<B$ then $A_{1} \ldots A_{n}$ as well as $B$ are true.

The notion of grounding raises a vexed question: what grounds the grounding facts? That is, what should we write in the place of $\mathrm{X}_{1} \ldots \mathrm{X}_{\mathrm{k}}$ in claims of the form,

$$
\mathrm{X}_{1} \ldots \mathrm{X}_{\mathrm{k}}<\left(\mathrm{A}_{1} \ldots \mathrm{A}_{\mathrm{n}}<\mathrm{B}\right) \text { ? }
$$

Call this the Question of Iterated Grounding (QIG). ${ }^{5}$ The question is important for a number of reasons. First, grounding is usually thought of as a "level-connector": a relation that connects fundamental

\footnotetext{
${ }^{3}$ Rosen (2010), Trogdon (2013), Skiles (2015) and Dixon (2016), among others, treat rounding as a relation between facts, while Rodriguez-Pereyra (2005) and Schaffer (2009) construe it as a category-neutral relation.

${ }^{4}$ See Fine 2012 for a discussion of the conceptual link between full and partial grounding.

5 The question has first been raised by Sider (2011: 106-107) more generally about fundamentality and level-connecting notions and by Bennett (2011) specifically about grounding.
} 
bits of reality to non-fundamental bits. As a result, it's often taken to be the right notion to express general philosophical theses to the effect that facts of a certain type constitute the full basis for other facts. This raises some questions about the status of the connecting facts themselves. One concerns a doctrine Sider dubbed "Purity", according to which fundamental facts feature only fundamental notions (2011: 106). If Purity is true, it's hard to see how facts about grounding could be fundamental. These facts involve both the grounds and what they ground, and the latter (being themselves grounded) are bound to be non-fundamental. But if the grounding facts are nonfundamental, they require further facts to ground them, which (for similar reasons) cannot be fundamental and require yet further grounds... and so we are off to an infinite regress.

Second, Dasgupta (2014b) raises a closely related problem for physicalism, though as he notes, the problem applies to any general level-connecting thesis according to which all facts are grounded in fundamental facts of a certain sort. If physicalism is understood as the doctrine that all fundamental facts are physical, then what should we think of facts about physical facts grounding non-physical facts? If those facts are ungrounded and thus fundamental, then some fundamental facts are not physical, after all. But if they are grounded, then once again we face a regress: what grounds the facts that in turn ground the facts about the physical facts grounding the non-physical facts? And what grounds those facts? And so on. Whether either Sider's or Dasgupta's regress is vicious is a contentious issue. Although there's a good case to be made that these regresses ultimately don't threaten the well-foundedness of grounding, one might still be wary of positing an infinite series of increasingly complex grounding facts. ${ }^{6}$

Third, and finally, answering the question of what (if anything) grounds the grounding facts might give us a deeper understanding of the nature of grounding. Extant answers to QIG have

\footnotetext{
${ }^{6}$ Bennett (2011: 30) asserts that the regress violates the well-foundedness of grounding; Dixon (2016) and Rabin and Rabern (2016) independently argue that the regress is consistent with any salient way of understanding well-foundedness.
} 
weighty implications for whether grounding is a superinternal relation (i.e., whether the existence of the grounding facts by itself suffices for those facts to ground the grounded facts) ${ }^{7}$ and for the relation between grounding and other notions, including essence ${ }^{8}$, metaphysical lawhood ${ }^{9}$, and a non-factive cousin of grounding ${ }^{10}$. For this reason, even if QIG falls short of posing a paradox, it still raises a question interesting enough on its own right to merit addressing.

In the present paper, I don't wish to defend any particular answer to QIG. Instead, I will argue that an important consideration that crucially bears on it has been neglected: the exact relation between grounding and metaphysical explanation. Lately, it has become standard to distinguish between grounding qua a metaphysical type of explanation and grounding qua the relation that "backs" such explanations. In section 2, I will show that once we recognize this distinction, we can distinguish no fewer than four questions in the vicinity of QIG. In section 3, I will examine the popular but vague slogan that grounding "backs" metaphysical explanation and argue that backing is itself best understood as a special case of metaphysical explanation. In the sections to follow (sections 4-7) I will argue that depending on whether grounding is identical to or merely "backs" metaphysical explanation, many versions of QIG have answers that are trivially entailed by the respective conception of grounding. The main exception is what I will call the "Question of Producing Production", which I will suggest is the question future inquiries into QIG should primarily focus on (although by then we will have seen that for many grounding theorists this question doesn't even arise). The main upshot will be that QIG cannot be tackled in isolation from

\footnotetext{
${ }^{7}$ Bennett 2011, 2017: Ch. 7, deRosset 2013; cf. Litland 2015, Loss 2015, and Carnino 2017

${ }^{8}$ Dasgupta 2014b; cf. Rosen 2010, Audi 2012a, 2012b, and Fine 2012

${ }^{9}$ See Wilsch 2016 and Schaffer 2017a, 2017b. See also Rosen 2006, Kment 2014 (Ch. 6), and Glazier 2017, though note that these three authors also assign an important role to essence in characterizing metaphysical laws.

${ }^{10}$ Litland 2017.
} 
the question of how grounding is related to explanation and that no matter how we spell out the connection, it will bear on QIG in hitherto unnoticed ways. ${ }^{11}$

\title{
2. What question of iterated grounding?
}

Above I described grounding as an "explanatory relation", and in particular as the relation at issue in metaphysical explanations. As an increasing number of grounding theorists have noted in recent years, this description is ambiguous. The phrase "explanatory relation" could mean a species of the general relation of explanation. Thus understood, 'grounding' is simply another word for

\footnotetext{
${ }^{11}$ Jessica Wilson (2014: 568 n80, 2018) has recently argued that QIG is a pseudo-problem. On her view grounding is a disjunction of "small-g grounding relations" (realization, the determinate-determinable relation, token identity, and other relations widely recognized before the "grounding revolution"), and QIG is an artifact of the "abstract nature of Grounding” (2018: 507) that doesn’t arise with “small-g” grounding relations. She writes:
}

\begin{abstract}
"If someone tells you that mental states are determinables of physical determinates, there's no temptation to ask, 'But in virtue of what do they stand in the determinable-determinate relation? [...] In the twenty-four years since Yablo $[\ldots]$ suggested that $[\ldots]$ mental states [were] determinables of physical states, there have been many critical discussions of this view [...] but not one has raised these sorts of meta-level dependence questions.” (2018: 508; emphasis in the original)
\end{abstract}

I think Wilson is mistaken on both counts. First, these questions make perfect sense; even if it had been true that nobody had asked them in the relevant literatures, it would just be all the worse for those literatures. Second, these questions have been asked. The issue of what grounds/explains the identity facts lately received considerable attention (see Shumener 2017 for an overview) and was problematized even before grounding appeared on the stage (Chalmers and Jackson 2001). Moreover, Ehring defends a variant of Wilson's own (1999) subset account of realization on the basis that it provides a "metaphysical explanation for why the sets of causal powers of mental properties stand in the subset relation to the sets of causal powers of certain physical properties" (2011: 172; emphasis in the original) and also extends this view to the determinate-determinable relation (2011: 139-143). 
metaphysical explanation. ${ }^{12}$ Alternatively, "explanatory relation" is often used for the kinds of relations that "back" or "underlie" metaphysical explanations; a sort of "metaphysical causation". Understood this way, 'grounding' means not metaphysical explanation but the relation (be it either a single unified relation or a disjunction of relations, a la J. Wilson) that underlies metaphysical explanation. ${ }^{13}$ If there is such an underlying relation, then that relation is to metaphysical explanation what causation is to scientific explanation. Following the terminology I introduced in my earlier work (Kovacs 2017), I will refer to the relation that putatively "backs" metaphysical explanation as 'production'.

The distinction between production and metaphysical explanation resembles a similar one Raven (2015) draws between "Separatist" and "Unionist" views, where the former identify grounding with the underlying relation whereas the latter with metaphysical explanation itself. However, I see Raven's taxonomy as an indirect way of getting at the more fundamental distinction between production and metaphysical explanation. Strictly speaking, the Separatism/Unionism debate is merely verbal: it's about how to use the word 'grounding'. ${ }^{14}$ Separatism is just the view that there is a relation of production beside metaphysical explanation, amended with the semantic claim that this relation is the meaning of 'grounding'. More problematically, even unionists are free to believe in production so long as they reserve 'grounding' for metaphysical explanation. In what follows, I will primarily focus on the distinction between production and metaphysical explanation,

\footnotetext{
12 Proponents of this conception include Fine (2001, 2012), Raven (2012), deRosset (2013), Dasgupta (2014a, 2014b, 2017), and Litland (2017), among others.

${ }^{13}$ This conception of grounding has been endorsed, for example, by Schaffer (2009, 2016, 2017a, 2017b), Audi (2012a, 2012b), Leuenberger (2014), Skiles (2015) and A. Wilson (2018). Schaffer and A. Wilson explicitly refer to grounding as "metaphysical causation".

${ }^{14}$ See also Dasgupta 2017: $94 \mathrm{n} 8$ for this point.
} 
irrespective of which of the two deserves to be called 'grounding'. In my official formulations, ' $<$ ' will thus henceforth receive an index depending on whether it's used to express metaphysical explanation or production; the former I will represent with ' $<_{\mathrm{e}}$ ' and the latter with ' $<_{\mathrm{p}}$ ' (I will keep using the indexless ' $<$ ' in contexts where the ambiguity is intended). ${ }^{15}$

Let me say a little more about 'production'. Henceforth I will use this word as a placeholder for whichever relation or family of relations "backs" metaphysical explanation, if there is any. More neutrally: the connective ' $<_{p}$ ' in ' $A_{1} \ldots A_{n}<_{p} B$ ' will express whichever connection is "responsible" for the truth of ' $A_{1} \ldots A_{n}<{ }_{e} B$ ' (or perhaps ' $A_{1} \ldots A_{n}, C_{1} \ldots C_{k}<{ }_{e} B$ ', where $C_{1} \ldots C_{k}$ are ancillary conditions that don't themselves play a role in producing B-more on this in a moment). Most theorists of metaphysical explanation adopt a model of explanation on which all explanations are "backed" or "undergirded" by worldly relations of determination. This picture is sometimes called (misleadingly, in my view) "explanatory realism"; I prefer to use the less theoretically loaded name "Backing Model". ${ }^{16}$ All separatists accept the Backing Model; typically, though not always, they single out grounding as the relation that backs all metaphysical explanations. Less obviously, many unionists

\footnotetext{
15 Schaffer (2016) has recently argued that the connective formulation is not well suited for grounding as the "underlying" connection, just like it wouldn't be suitable for a worldly relation of causation. I think he is wrong about this (causation itself can be expressed with a connective, without reifying the causal relata; see, e.g., van Inwagen 2012: 164-165 and Skow 2016: 33-34), and at any rate my choice to express grounding with a connective makes little difference to the argument of this paper. More generally, the controversy between connective and relational views strikes me as entirely orthogonal to the Separatism/Unionism debate.

${ }^{16}$ Here, too, I use terminology that I introduced in my earlier work (Kovacs forthcoming-1). Advocates of the Backing Model include Ruben (1990), Kim (1994), and Skow (2016). The name "explanatory realism" is misleading because explanation might be an objective matter (in the sense of being mind-independent) without being "backed" by explanatory relations; see Friedman 1974: 7-8. See also Kovacs 2017, forthcoming-1 and Taylor 2018 for objections to the Backing Model.
} 
accept the Backing Model too; they just differ from separatists in the range of relations they posit to back explanations. For example, an increasingly popular strand of theorizing traces metaphysical explanations back to essences. ${ }^{17}$ As I use the word 'production', the resulting relation of essential connectedness - insofar as it "backs" metaphysical explanation-counts as a kind of production. So do J. Wilson's “small-g” grounding relations. ${ }^{18}$

Proponents of the Backing Model have three possible options regarding the relation between production and metaphysical explanation. The simplest view is that nothing needs to be added to production for metaphysical explanation; the former is by itself sufficient for the latter. ${ }^{19} \mathrm{~A}$ second possibility is that production needs to be amended by "ancillary conditions", for example metaphysical laws ${ }^{20}$ or the satisfaction of certain epistemic and/or pragmatic criteria ${ }^{21}$, to get a complete explanation. These ancillary factors are part of what explain the metaphysical explananda, but they aren't among the facts that produce them. A third option is that ancillary conditions do play a role in metaphysical explanations, but they are also among the producers. For example, perhaps some facts bear a multitude of different small-g grounding relations to an explanandum, which makes all of them qualify as its producers but only some of them as ancillary conditions. I don't mean to rule out this possibility, but in what follows I will treat it as a special case of the first option.

\footnotetext{
17 See Rosen 2010, Fine 2012, and Correia 2013; see also Audi 2012a, 2012b, Kment 2014: Ch. 6, and Glazier 2017 (although the latter three count as separatists according to Raven's taxonomy).

18 Some authors distinguish between grounding-based and essentialist explanations (Kment 2014: 164, Glazier 2017).

When I count essential connectedness as a type of production, I don't mean to beg the question against such views; rather, I use 'production' stipulatively for any relation that plays a "backing" role in metaphysical explanations similar to that of grounding (as understood by such essentialists).

${ }^{19}$ This seems to be the view of Skiles (2015), Skow (2016), and A. Wilson (2018).

20 See Kment 2014: Ch 6 and Schaffer 2017a, 2017 b.

${ }^{21}$ See Audi 2012b: 119-120, deRosset 2013: 13, and Trogdon 2018: 1295-6.
} 
The main distinction I'm interested in here, and which I will use to map logical space, is between views that assert and views that deny that every partial metaphysical explanans of a fact is also a partial producer of that fact. In that taxonomy, ancillary conditions that are a special type of producer are producers nonetheless. ${ }^{22}$ This means that all of the "simple" views I will discuss in sections 4-7 will have sub-varieties that recognize a distinction between "mere" producers and producers that have the special status of also being ancillary conditions. But as far as I can see the existence of this sub-category doesn't affect my discussion of those views (at least not at the level of abstraction at which I will consider them). For this reason, in what follows I will stipulatively use the expression 'ancillary conditions' only for things that occur in the explanans base but not in the production base of a metaphysical explanandum.

For simplicity's sake, in what follows I will collectively refer to all proponents of the Backing Model (whether they accept one type of production or many, and whether they think that production needs to be amended with ancillary conditions to yield a full explanation) as production theorists or p-theorists. They can be contrasted with grounding theorists who don't commit themselves to any underlying relation to back metaphysical explanation. While this is a coherent combination of views, few defended it in print; as we have seen, those who deny that there is a single relation underlying metaphysical explanations nonetheless tend to agree that something underlies them. At any rate, I will refer to those who reject the Backing Model as explanation theorists or e-theorists. $^{23}$

\footnotetext{
22 Thanks to an anonymous referee for requesting more clarity about the status of ancillary conditions.

${ }^{23}$ I first introduced this terminology in Kovacs 2017. Views of metaphysical explanation that explicitly decline to assign any role to "underlying" or "backing" relations have been defended by Shaheen (2016), Kovacs (2017, forthcoming-1, forthcoming-2) and Miller and Norton (2017, forthcoming) and seriously considered by Thompson (2016) and Dasgupta (2017).
} 
Once we are clear about the distinction between production and metaphysical explanation, we can distinguish four sub-questions that could be meant by QIG:

(i) The Question of Explaining Explanation: What are $\mathrm{X}_{1} \ldots \mathrm{X}_{\mathrm{k}}$ such that $\mathrm{X}_{1} \ldots \mathrm{X}_{\mathrm{k}}<_{\mathrm{e}}\left(\mathrm{A}_{1} \ldots \mathrm{A}_{\mathrm{n}}<_{\mathrm{e}} \mathrm{B}\right)$ ?

(ii) The Question of Producing Explanation: What are $\mathrm{X}_{1} \ldots \mathrm{X}_{\mathrm{k}}$ such that $\mathrm{X}_{1} \ldots \mathrm{X}_{\mathrm{k}}<_{\mathrm{p}}\left(\mathrm{A}_{1} \ldots \mathrm{A}_{\mathrm{n}}<\mathrm{e}\right)$ ?

(iii) The Question of Producing Production: What are $\mathrm{X}_{1} \ldots \mathrm{X}_{\mathrm{k}}$ such that $\mathrm{X}_{1} \ldots \mathrm{X}_{\mathrm{k}}<_{\mathrm{p}}\left(\mathrm{A}_{1} \ldots \mathrm{A}_{\mathrm{n}}<\mathrm{p}\right)$ ?

(iv) The Question of Explaining Production: What are $\mathrm{X}_{1} \ldots \mathrm{X}_{\mathrm{k}}$ such that $\mathrm{X}_{1} \ldots \mathrm{X}_{\mathrm{k}}<_{\mathrm{e}}\left(\mathrm{A}_{1} \ldots \mathrm{A}_{\mathrm{n}}<_{\mathrm{p}} \mathrm{B}\right)^{24}$

Note that while questions (ii)-(iv) arise only for p-theorists, everybody has to face question (i). For this reason, it is advisable to start with this disambiguation of QIG. But before doing so, I need to address one more crucial preliminary issue: the question of how we should understand the popular but under-examined slogan that a relation "backs" metaphysical explanation. As it will soon become clear, my answer to this question plays a central role in making (i) and (ii) easy to answer for ptheorists.

\section{Backing}

P-theorists frequently say that grounding "backs" metaphysical explanation. But what does it mean to say that grounding (or any relation, for that matter) "backs" metaphysical explanation? This question is rarely discussed in the literature but will be important for much of what follows. I can think of two major candidates. The first one is that "backing" is itself a case of (full) metaphysical

\footnotetext{
${ }^{24}$ Perhaps (ii) and (iv) are not strictly speaking disambiguations of QIG, since they use 'grounding' with two different meanings in the same question. Still, they are in the close vicinity of QIG and will be instrumental in addressing other disambiguations, so I will treat them as such.
} 
explanation. Using 'production' as a placeholder for whatever backs metaphysical explanation, this gives us the following thesis:

Backing-iff-Full-Explanation (BFE): Production backs metaphysical explanation iff

$$
\square\left(\left(A_{1} \ldots A_{n}<_{e} B\right) \rightarrow\left(\left(A_{1} \ldots A_{n}<_{p} B\right)<_{e}\left(A_{1} \ldots A_{n}<{ }_{e} B\right)\right)\right) .{ }^{25}
$$

Different p-theorists can fill in the ' $<_{\mathrm{p}}$ ' in BFE in different ways: some will think it's facts featuring a unified relation of grounding that metaphysically explain the metaphysical explanation facts, while others might hold that it's facts featuring various determination relations. What's common to all versions is that they understand backing as full metaphysical explanation: if production backs explanation, then whenever $A_{1} \ldots A_{n}$ produce $B$, this is by itself sufficient for $A_{1} \ldots A_{n}$ to also metaphysically explain B. While BFE has rarely been stated explicitly (though see the citations in the previous footnote), it's a reasonable interpretation of what at least some p-theorists mean when they say that grounding backs metaphysical explanation. P-theorists often freely go back-and-forth between grounding and metaphysical explanation, officially distinguishing the two but often using the one to infer various features of the other. This practice makes sense if one accepts BFE as a background assumption. ${ }^{26}$

The most plausible alternative to BFE I can think of is that production partially explains metaphysical explanation and requires some ancillary conditions to fully explain it. This interpretation is encouraged by remarks made by some grounding theorists to the effect that there is

\footnotetext{
${ }^{25}$ See Rodriguez-Pereyra 2005: 28, Schnieder 2010: 326-8 and Kovacs 2017: 2934 for similar interpretations of 'backing'-talk.

${ }^{26}$ Though see Maurin forthcoming for an argument to the effect that more than anything, this practice indicates a serious problem with the relevant conception of grounding.
} 
a gap between grounding and metaphysical explanation, whereby something extra, e.g. laws or epistemic conditions, needs to be added to the former in order to get the latter (see footnotes 2021). Then we can propose the following as a second possible interpretation of the idea that production backs metaphysical explanation (in the definitions that follow, ' $\mathrm{C}$ ' and its indexed variants will henceforth stand for ancillary conditions):

(Backing-iff-Partial-Explanation, BPE) Production backs metaphysical explanation iff $\square\left(\left(A_{1} \ldots A_{n}<{ }_{e} B\right) \rightarrow\left(\left(\left(A_{1} \ldots A_{n}<p\right), C_{1} \ldots C_{k}\right)<{ }_{e}\left(A_{1} \ldots A_{n}<{ }_{e} B\right)\right)\right)$.

(Informally: necessarily, if $A_{1} \ldots A_{n}$ metaphysically explain $B$, then $A_{1} \ldots A_{n}$ 's metaphysically explaining $B$ is metaphysically explained by $A_{1} \ldots A_{n}$ 's producing $B$ and ancillary conditions $C_{1} \ldots C_{k}$.) BFE and BPE also have their production-based analogues: perhaps production backs metaphysical explanation in the sense that the production facts fully or partially produce the metaphysical explanation facts (in the latter case along with ancillary conditions). However, given the way I understand production here, these options (with one minor caveat, which I will explain shortly) aren't really competitors of the two views described above. This is especially clear when we identify backing with full production. Since on this view production is sufficient on its own for metaphysical explanation, any facts that produce a metaphysical explanation fact automatically metaphysically explain that metaphysical explanation fact, too. Moreover, since I'm using 'production' for whatever backs metaphysical explanation, any facts that metaphysically explain a metaphysically explanation fact also produce that fact. Thus on this kind of view, even if 'backing' means full production rather than full metaphysical explanation, we nonetheless get the biconditional encapsulated by BFE: production backs metaphysical explanation iff the production facts metaphysically explain the metaphysical explanation facts. 
Things are trickier on the assumption that backing is only partial production. Simply replacing 'metaphysically explain' with 'produce' in the definition of backing would yield the following thesis:

Backing-iff-Partial-Production (BPP): Production backs metaphysical explanation iff $\square\left(\left(A_{1} \ldots A_{n}<_{e} B\right) \rightarrow\left(\left(A_{1} \ldots A_{n}, C_{1} \ldots C_{k}<{ }_{p} B\right)<_{e}\left(A_{1} \ldots A_{n}<{ }_{e} B\right)\right)\right)$.

(Informally: Necessarily, if $A_{1} \ldots A_{n}$ metaphysically explain $B$ then $A_{1} \ldots A_{n}$ 's metaphysically explaining $B$ is explained by $A_{1} \ldots A_{n}$ and ancillary conditions $C_{1} \ldots C_{k}$ jointly producing B.) However, BPP cannot be right. We distinguished producers from ancillary conditions in order to put a wedge between production and metaphysical explanation, so the ancillary conditions that help explain B cannot be among its producers. (Recall that this is a consequence of how we cut up the terrain in section 2: would-be ancillary conditions that are among the producers would already be accounted for in BFE, since they would be among the $A_{1} \ldots A_{n}$ that produce as well as metaphysically explain B). So, p-theorists who want to understand backing in terms of partial explanation should accept the very same thesis about production that proponents of BFE are already committed to, namely BFP: $A_{1} \ldots A_{n}$ 's metaphysically explaining $B$ is explained by $A_{1} \ldots A_{n}$ jointly producing $B$ and ancillary conditions $C_{1} \ldots C_{k}-$ but $C_{1} \ldots C_{k}$ aren't themselves among the producers of $B$.

Hopefully this clarifies the tangled relation between backing, grounding, production and metaphysical explanation. Since it's not customary to explicitly say what backing is, it might be helpful to reiterate how I see the space of conceptual possibilities here. P-theorists who don't believe that metaphysical explanations require ancillary conditions should accept both BFE and BFP. They can pick whichever they prefer as their official definition of 'backing' but should still accept the other as a true biconditional. By contrast, p-theorists who do require ancillary conditions can choose between BPE and BFP. In the former case, the production facts will serve as partial explanantia that, 
amended with ancillary conditions, fully explain the metaphysical explanation facts. In the latter case, the production facts will provide a full production base, although they still need to be amended with ancillary conditions to fully explain the metaphysical explanation facts. As far as I can see, the difference between these two options is largely verbal: they both imply that production facts fully produce and partially explain the metaphysical explanation facts and only differ in which of these relations should be meant by the word 'backing'. So, in what follows I will treat them together.

A third, more deflationary, interpretation of 'backing'-talk could be that production backs metaphysical explanation simply in the sense of being "tracked" by it. ${ }^{27}$ That is, the job of metaphysical explanations is to give information about the worldly relations of production, and it is only in this weak sense that the latter "back" the former. ${ }^{28}$ However, I don't think this proposal gives us a clear alternative to the options discussed above, since the expression 'gives information' can be understood in multiple ways. One sense in which metaphysical explanations could "give information" is by being representational (e.g. linguistic) things that express the production facts. ${ }^{29}$ But saying that our 'metaphysically explain'-sentences express facts about production is just another way of saying that metaphysical explanation is grounding-a view I already discussed above. Alternatively, one could maintain that 'metaphysical explanation'-sentences give information about production in some more indirect way. Maybe so, but this doesn't yet tell us what the connection is between metaphysical explanation and production. The main intuition behind "backing"-talk is that production is prior to metaphysical explanation, rather than the other way round. My proposal to understand backing in terms of explanation is a way to make sense of this priority intuition, whereas

\footnotetext{
27 Thanks to Jonathan Shaheen for drawing my attention to this possibility.

${ }^{28}$ Glazier (forthcoming) briefly mentions this possibility.

${ }^{29}$ I think deRosset (ms: Ch. 1) has in mind a similar view when suggesting that the Unionism/Separatism debate is confused.
} 
the bare claim that metaphysical explanation has consequences for production is fully consistent with the view that production is downstream from metaphysical explanation. ${ }^{30}$

Since thus far discussions explicitly about backing have been largely absent from the literature, clear endorsements of any of the abovementioned theses are rare (though see footnote 25). I still find it plausible that either $\mathrm{BFE}$ or $\mathrm{BPE} / \mathrm{BFP}$ has to be right partly on interpretative grounds and partly because I don't see plausible alternatives. It is therefore important to note that one p-theorist, Paul Audi, explicitly declines to spell out backing in terms of either grounding or explanation. He reasons as follows:

"I take grounding to be a singular relation between facts, but it seems to me that grounding relations depend on and follow from the natures of the properties involved in these facts. [...] It might seem, then, that we can use the notion of essential connectedness to explain what grounds what. [...] [But the] principle [that] the fact that any given grounding relation holds is itself grounded in the fact that the properties in one fact are essentially connected to the properties in the other [...] faces a number of difficulties. Start with some grounding fact:

(4) $[\mathrm{x}$ is maroon] grounds [x is red].

The principle requires that this fact be grounded in the fact that the properties in each fact are essentially connected. So we have:

(5) $[\mathrm{EC}($ maroonness, redness) $]$ grounds [[x is maroon] grounds [x is red]].

But now the principle requires that (5) be grounded in an essential-connection fact, one connecting the properties in the grounding fact (in this case, itself about essential connection) with those in the grounded fact (in this case, the first-order grounding fact). We immediately face the threat of regress and a proliferation of iterated facts about essential connection.” (Audi 2012a: 693-694)

In effect, Audi worries about a version of QIG: if the grounding facts "follow from" the essence facts by being grounded (produced) by them, we are off to a regress. And it's easy to see how one

30 This would be a grounding analogue of causal idealism (cf. footnote 32). 
could raise a similar worry about the grounding facts "backing" the metaphysical explanation facts by metaphysically explaining them. However, this doesn't strike me as a strong motivation against identifying backing with metaphysical explanation. It's up for grabs whether the regress Audi mentions actually arises, and if so, whether it's vicious. It suffices to note that it makes little difference to the regress whether we state it in terms of backing or grounding. If it's legitimate to ask what grounds the grounding facts, then it makes just as much sense to ask what grounds the backing facts. Audi's regress arises solely because (5) is prima facie apt for a grounding explanation; whether it features grounding or a primitive backing relation is neither here nor there.

I conclude that we should interpret the slogan that grounding or some other relations (collectively: production) back metaphysical explanation in terms of either metaphysical explanation or production. Doing so is both justified on interpretative grounds and necessary to avoid shrouding a central idea of the Backing Model in mystery. Moreover, resisting this reductive characterization has no obvious advantage.

Here's where we are now. We have four questions of iterated grounding, one arising for everyone and three others arising only for p-theorists. We also have four possible interpretations of "backing"-talk, which (I argued) can be reduced to two for all purposes that matter. Armed with these distinctions, we can now look afresh at QIG, or rather, the four sub-questions it disambiguates into. I will start with the most complex and perhaps most fundamental of these questions, the Question of Explaining Explanation.

\section{The Question of Explaining Explanation}

Our question is what in section $2 \mathrm{I}$ introduced as

The Question of Explaining Explanation. What are $\mathrm{X}_{1} \ldots \mathrm{X}_{\mathrm{k}}$ such that $\mathrm{X}_{1} \ldots \mathrm{X}_{\mathrm{k}}<_{\mathrm{e}}\left(\mathrm{A}_{1} \ldots \mathrm{A}_{\mathrm{n}}<\mathrm{e}\right)$ ? 
As it will later emerge, starting with this question has strategic advantages, since certain answers to it automatically settle some of the other questions. We should distinguish two possibilities: (a) production backs metaphysical explanation; (b) production doesn't back metaphysical explanation. Moreover, in line with the foregoing discussion of backing, we can distinguish two sub-cases within (a): (aa) the production facts fully metaphysically explain the metaphysical explanation facts, or (ab) the production facts fully produce the metaphysical explanation facts but fully explain them only in tandem with ancillary conditions.

\subsection{BFE and the answer to The Question of Explaining Explanation}

If production backs metaphysical explanation, and this implies that the production facts fully metaphysically explain the metaphysical explanation facts (as BFE has it), we immediately get an answer to the Question of Explaining Explanation. It goes as follows:

\section{Simple Productionism about Explaining Explanation:}

$$
\square\left(\left(A_{1} \ldots A_{n}<{ }_{e} B\right) \rightarrow\left(\left(A_{1} \ldots A_{n}<{ }_{p} B\right)<{ }_{e}\left(A_{1} \ldots A_{n}<{ }_{e} B\right)\right)\right)
$$

In words: necessarily, for any metaphysical explanation fact $\mathrm{E}, \mathrm{E}$ is metaphysically explained by the production of E's explanandum by E's explanantia. Of course, since every metaphysical explanation fact is metaphysically explained by a production fact, this simple answer also applies to iterated explanations (from now on, in longer formulas I will set occurrences of ' $<_{\mathrm{p}}$ ' and ' $<_{\mathrm{e}}$ ' as the main connective in bold). For example, $\left(A_{1} \ldots A_{n}<{ }_{p} B\right)<_{e}\left(A_{1} \ldots A_{n}<{ }_{e} B\right)$ is metaphysically explained by $\left(A_{1} \ldots A_{n}<{ }_{p} B\right)<_{p}\left(A_{1} \ldots A_{n}<{ }_{e} B\right)$. And the explanation of why the latter metaphysically explains the former is $\left(\left(A_{1} \ldots A_{n}<{ }_{p} B\right)<_{p}\left(A_{1} \ldots A_{n}<{ }_{e} B\right)\right)<_{p}\left(\left(A_{1} \ldots A_{n}<p\right)<_{e}\left(A_{1} \ldots A_{n}<{ }_{e} B\right)\right)$ - and so on. The 
general recipe for getting the explanantia of any metaphysical explanation fact is to keep its explanans and explanandum clauses fixed and "replace" the relation of metaphysical explanation between them with the relation of production.

\subsection{BPE/BFP and the answer to The Question of Explaining Explanation}

Perhaps the production facts only partially explain the metaphysical explanation facts and need to be amended by ancillary conditions (metaphysical laws, epistemic constraints, or something similar) in order to yield a complete explanation of the explanation facts. A tempting first-pass answer along these lines to the Question of Explaining Explanation might go as follows:

Nä̈ve Ancillary Productionism about Explaining Explanation:

$$
\square\left(\left(A_{1} \ldots A_{n}, C_{1} \ldots C_{k}<e\right) \rightarrow\left(\left(A_{1} \ldots A_{n}, C_{1} \ldots C_{k}<{ }_{p} B\right)<_{e}\left(A_{1} \ldots A_{n}, C_{1} \ldots C_{k}<{ }_{e} B\right)\right)\right)
$$

In words: necessarily, if $A_{1} \ldots A_{n}$ and ancillary conditions $C_{1} \ldots C_{k}$ metaphysically explain $B$, they do so because $A_{1} \ldots A_{n}$ and $C_{1} \ldots C_{k}$ produce $B$. However, Naïve Ancillary Productionism doesn't work as it stands. This is because it implies that $C_{1} \ldots C_{k}$ are among the producers of $B$. But, as we have already discussed in section 3, ancillary conditions (as I understand them) are not supposed to be producers; the whole point of introducing them was to distinguish their role from that of the producers in metaphysical explanations.

The solution is to systematically "remove" Ancillary Conditions from the production base and add them to the explanans base as a sui generis type of explanans. In the case of a metaphysical explanation whose explanans clause doesn't itself involve metaphysical explanation, this method will

give us that $\left(A_{1} \ldots A_{n}<p\right), C_{1} \ldots C_{k}<<_{e}\left(A_{1} \ldots A_{n}, C_{1} \ldots C_{k}<{ }_{e} B\right)$. And the explanation of this fact will look like this: 


$$
\begin{aligned}
& \left(\left(\left(A_{1} \ldots A_{n}<_{p} B\right)<_{p}\left(A_{1} \ldots A_{n}, C_{1} \ldots C_{k}<<_{e} B\right)\right), C_{1}^{\prime} \ldots C_{m}^{\prime}\right)<_{e}\left(\left(\left(A_{1} \ldots A_{n}<_{p} B\right), C_{1} \ldots C_{k}\right)<_{e}\right. \\
& \left.\left.\left(A_{1} \ldots A_{n}, C_{1} \ldots C_{k}<_{e} B\right)\right)\right)
\end{aligned}
$$

This suggests a general recipe. When looking for the sentence that explains a metaphysical explanation sentence, S, (i) replace S's main connective ' $<_{e}$ ' with ' $<_{p}$ ', (ii) remove any ancillary conditions that appear as producers in the production base of S's explanans clause, and then (iii) add ancillary conditions (the original ones or some new ones-see below) as extra explanantia if necessary. More generally:

\section{Sophisticated Ancillary Productionism about Explaining Explanation:}

$$
\square\left(\left(A_{1} \ldots A_{n}, C_{1} \ldots C_{k}<{ }_{e} B\right) \rightarrow\left(\left(A_{1} \ldots A_{n}<p, B, C_{1}^{\prime} \ldots C_{m}^{\prime}\right)<_{e}\left(A_{1} \ldots A_{n}, C_{1} \ldots C_{k}<e s\right)\right)\right)
$$

Informally: necessarily, if $A_{1} \ldots A_{n}$ and ancillary conditions $C_{1} \ldots C_{k}$ jointly metaphysically explain $B$, then this, in turn, is metaphysically explained by $A_{1} \ldots A_{n}$ producing $B$ and ancillary conditions $\mathrm{C}_{1} \ldots \mathrm{C}_{\mathrm{m}}$. There is an important question that this principle leaves open: are $\mathrm{C}_{1} \ldots \mathrm{C}_{\mathrm{m}}$ identical to $\mathrm{C}_{1} \ldots \mathrm{C}_{\mathrm{k}}$ ? That is, when some $\mathrm{C}_{1} \ldots \mathrm{C}_{\mathrm{k}}$ play the role of ancillary conditions in the explanans base of a metaphysical explanation $\mathrm{E}$, can $\mathrm{C}_{1} \ldots \mathrm{C}_{\mathrm{k}}$ also play the very same role in the explanans base of a higher-order explanation whose explanandum is $\mathrm{E}$ or some additional ancillary conditions are needed? This is a substantive issue I cannot settle here. Nothing in the above formulation requires $\mathrm{C}_{1} \ldots \mathrm{C}_{\mathrm{k}}$ be identical to $\mathrm{C}_{1}{ }_{1} \ldots \mathrm{C}_{\mathrm{m}}$, but if ancillary conditions are laws, I can see why one might be reluctant to admit an infinite number of metaphysical laws (perhaps an infinite number of possible epistemic constraints is less objectionable). ${ }^{31}$ Suffice it to say that one version or other of

\footnotetext{
31 See Schaffer (2017b: 316) for a related discussion (he argues that some metaphysical laws are fundamental).
} 
Sophisticated Ancillary Productionism is a natural way to make sense of the idea that each metaphysical explanation fact is explained by its producers, along with some ancillary conditions that serve as its explanantia but not qua producers.

\subsection{Beyond the Backing Model}

In the previous two sub-sections I considered answers to the Question of Explaining Explanation that automatically fall out of natural interpretations of the Backing Model. But what if the Backing Model is false and metaphysical explanations aren't backed by production? Since I have been using 'production' simply for the relation supposedly backing metaphysical explanation, this would imply that metaphysical explanations aren't backed by anything: not by grounding, not by essential connectedness, and not by "small-g" grounding relations or anything similar. How should we then approach the Question of Explaining Explanation?

This question is difficult to answer with full generality because it would require us to know what a salient alternative to the Backing Model would look like, but few have bothered to develop one in detail. At this point, it's worth emphasizing again that Unionism (in Raven's sense) by itself doesn't amount to a rejection of the Backing Model. Unionism is just a view about how we should use the word 'grounding' and as such is fully consistent with the claim that metaphysical explanations are backed by non-causal determinative relations. Indeed, most unionists, while primarily interested in the phenomenon of metaphysical explanation, are happy to assume that these explanations work because of the determinative relations that "back" them.

I cannot offer here a complete survey of possible views that break with the Backing Model. What I can do is sketch one powerful alternative that used to be prominent in the philosophy of science and has in recent years made a bit of a comeback in metaphysics. According to a venerable tradition that can be traced back at least to Hempel and Oppenheim (1948), explanations are 
arguments of a certain sort. Now, to be sure, many grounding theorists agree that there is a tight connection between explanations and arguments. But on the kind of view I'm presently interested in, explanations (at least metaphysical ones) strictly and literally are arguments: a true sentence of the form ' $A_{1} \ldots A_{n}$ explain $B$ ' is shorthand for a sound argument in which $A_{1} \ldots A_{n}$ are premises, $B$ is the conclusion, and some further constraints are satisfied. Understanding explanations as arguments is particularly natural on what Strevens (2008: Ch. 1) aptly calls pattern subsumption views, and as a matter of fact, most argument views fit under this label. Pattern subsumption views see the essence of explanation as the subsumption of particular cases under general regularities: laws, law-like generalizations, and perhaps other general patterns. Of course, many (even most) proponents of the Backing Model will be happy to agree that generalizations play an important role in explanation. But pattern subsumption theorists think that properly understood, the patterns are all that there is to an explanation; what we would normally consider "backing" relations are at best downstream from these patterns. ${ }^{32}$

Argument views of metaphysical explanation can take a number of forms. Influenced by Hempel and Oppenheim's Deductive-Nomological account, Wilsch (2016) defends a DN model of metaphysical explanation, according to which explanations are deductively valid arguments with no non-redundant premises, at least one of which is a law of metaphysics. ${ }^{33}$ In my own work (Kovacs 2017, forthcoming-2) I take inspiration from Kitcher (1989) and defend a unificationist account,

\footnotetext{
32 This is most explicit in the work of Philip Kitcher, who in effect adopts a version of causal idealism: causal relations are projected onto the world as a by-product of our explanatory habits (1989: 496-7). See also Hempel 1965 : 362-4.

33 It somewhat complicates the picture that certain elements of Wilsch's view resemble the Backing Model. He understands the laws of metaphysics in terms of primitive "construction operations", for example composition and setformation; and the role of these operations is very similar to that of production relations. However, these niceties are irrelevant to my present concerns. Litland (2017) also defends a related view, but in his variant metaphysical laws don't occur as premises; rather, their role is played by inference rules.
} 
according to which metaphysical explanation is a holistic matter: an argument is explanatory just in case it instantiates an argument pattern that belongs to the most unified set of arguments, where the extent of unification is settled by a weighted set of criteria that (simplifying a bit) balance strength, simplicity and naturalness. And there may well be further, as of yet unoccupied, positions in logical space that also construe metaphysical explanations as arguments; the literature on scientific explanation witnessed countless variations and attempted improvements on the DN model ${ }^{34}$, and many of these may be at least as defensible in the metaphysical as in the scientific realm.

None of these details have much significance, however, so long as we stick with the idea that metaphysical explanations are arguments. Anybody who maintains at least this much can thereby deflect the Question of Explaining Explanation as one that simply doesn't arise. We can see why by getting explicit on what an explanatory argument is. Suppose that $A_{1} \ldots A_{n}$, perhaps along with some ancillary conditions, metaphysically explain B (to simplify matters I will ignore ancillary conditions for the rest of this section, since they don't make any difference to the present discussion). ${ }^{35}$ That is, $A_{1} \ldots A_{n}<{ }_{e} B$. Then the corresponding explanatory argument will have $A_{1} \ldots A_{n}$ as premises and $B$ as its conclusion:

\footnotetext{
34 See Brody 1972, McCarthy 1977 and Railton 1981, among many others.

35 Philosophers who assign some role to ancillary conditions differ on whether these should occur as premises in the argument should instead be treated more like inference rules that aren't themselves among the premises; see, e.g., deRosset 2013 for the former and Litland 2017 and Schaffer 2017a for the latter view. Again, while the issue is otherwise important, it has no bearing on any our present concerns. Note, however, that the version of the view I will defend below demands that at least logical laws not occur among the premises, even if other ancillary conditions might.
} 


\section{(Argument)}

$\mathrm{A}_{1}$

$A_{n}$

$\mathrm{B}$

According to argument views, it is strictly speaking Argument that we should count as an explanation. Or more precisely, it is Argument that counts as an explanation in the sense of 'explanation' that theorists of explanation should be interested in; $A_{1} \ldots A_{n}$ and $C_{1} \ldots C_{n}$ are also "explanations" in the sense that they are among the explanantia of the explanandum, B, but the explanatory product - that which is the proper focus of theories of explanation-is Argument. Argument is a more perspicuous way of expressing ' $A_{1} \ldots A_{n}$ metaphysically explain $B$ ' or 'B obtains because $A_{1} \ldots A_{n}$ obtain' (where 'because' receives a metaphysical reading). ${ }^{36}$

This is important because if explanations are arguments and their explananda are the conclusions of these arguments, then there cannot be such as thing as a higher-order explanation, i.e. an explanation whose explanandum is itself an explanation. Consider again the Question of Explaining Explanation: What are $\mathrm{X}_{1} \ldots \mathrm{X}_{\mathrm{n}}$ such that $\mathrm{X}_{1} \ldots \mathrm{X}_{\mathrm{n}}<_{\mathrm{e}}\left(\mathrm{A}_{1} \ldots \mathrm{A}_{\mathrm{n}}<_{\mathrm{e}} \mathrm{B}\right)$ ? If explanations are arguments, this question simply doesn't make sense. It translates into the question of what the premises of the explanatory argument are whose conclusion is another argument with B as its conclusion and $A_{1} \ldots A_{n}$ as its premises. But of course, there can be no such argument. Arguments are sequences of sentences, whereas their conclusions are sentences; thus, a sequence of sentences is

\footnotetext{
36 See White (1965: 17-22) for a more detailed discussion of the relation between explanation statements and explanatory arguments. I borrow the useful expression 'explanatory product' from Ruben (1990: 7-8).
} 
the wrong kind of thing to serve as the conclusion of an argument. It is therefore something like a category mistake to ask what explains an explanation, metaphysical or otherwise.

But can it be this easy to dissolve the Question of Explaining Explanation? On the basis of a similar reasoning, Litland (2017) has recently expressed sympathy with the idea that it's illegitimate to ask what explains an explanation. However, he maintains that even if we can dismiss QIG on such grounds, we are still left with a close cousin of it. To paraphrase Litland's formulation a bit, the residual question is what explains the truth of the proposition that there is an explanatory argument with $A_{1} \ldots A_{n}$ as its premises and $C$ as its conclusion.

In my view this question too has a relatively simple answer: the existence of such an argument is explained by $A_{1} \ldots A_{n}$. This can be made intuitive in two steps. First step: it's generally plausible that the existence of a sound argument is explained by its premises and its conclusion. Why is there a sound argument (explanatory or otherwise) with premises $A_{1} \ldots A_{n}$ and conclusion $B$ ? Because of $A_{1} \ldots A_{n}$ and $B$, which are all there is to the argument. ${ }^{37,38}$ Some might be tempted to add to the explanantia of there being an argument from $A_{1} \ldots A_{n}$ to $B$ the logical connection that $A_{1} \ldots A_{n}$ bear to $B$ (or inference rules, or logical laws, etc.), but this temptation should be resisted. For once we add this, it's unclear why we should sop there: why don't we also have to add as a separate explanans that

\footnotetext{
${ }^{37}$ One could try to further justify this step on the basis of the popular view that existential facts are grounded in their witnesses. There is an argument from $\mathrm{A}_{1} \ldots \mathrm{A}_{\mathrm{n}}$ to $\mathrm{B}$ because Argument is an argument from $\mathrm{A}_{1} \ldots \mathrm{A}_{\mathrm{n}}$ to $\mathrm{B}$. And Argument is an argument from $A_{1} \ldots A_{n}$ to $B$ because of $A_{1} \ldots A_{n}$ and $B$.

38 There might be a more general account of why there is a valid argument from $A_{1} \ldots A_{n}$ to $B$, whether that argument is sound or not (a valid but unsound argument obviously cannot have all of its premises as explanantia.) But explaining such arguments would require presupposing a non-factive notion of explanation, which goes far beyond the tools I'm presupposing here. Note also that all I attempt to do here is give $a$ true answer to each of the four questions of iterated grounding; as I note in the concluding section, some of these questions might have more than one true answer. Thanks to Jon Litland for helpful discussion here.
} 
if $A_{1} \ldots A_{n}$ and $B$ hold and $B$ is a logical consequence of $A_{1} \ldots A_{n}$ then there is an argument from $A_{1} \ldots A_{n}$ to $B$ ? Of course, the worry is similar to Lewis Carroll's famous infinite regress about deductive reasoning, and we can avoid it by insisting that $A_{1} \ldots A_{n}$ and $B$ by themselves explain why there is an argument from $A_{1} \ldots A_{n}$ to $B$.

Second step: if the argument is explanatory, then its conclusion is already fully explained by its premises. So while the existence of a sound argument from some premises to a conclusion is generally explained by the premises and the conclusion, in this special case we can make do with just the premises. That is, we can simplify the picture by saying that what explains the existence of an explanatory argument from $A_{1} \ldots A_{n}$ to $B$ are simply the argument's premises, $A_{1} \ldots A_{n}$-we don't need to separately add $\mathrm{B}$, which is already explained by these. ${ }^{39}$

It's not hard to see that the view we end up with borrows features from two different answers to QIG. With respect to the metaphysical explanations themselves it's a version of Trialism, the view that the grounding facts have the special status of not simply being ungrounded but not even being apt to be grounded. ${ }^{40}$ And with respect to facts about metaphysical explanation, it resembles what Litland (2017) calls the "Straightforward Account": $A_{1} \ldots A_{n}<B$ is grounded in $A_{1} \ldots A_{n}$ for any

\footnotetext{
${ }^{39}$ Note that the account sketched above is addressed to the question of why there is such and such an explanatory argument. But as an anonymous reviewer points out, there is also the subtly different question of why such and such an argument is explanatory. The answer to this latter question should, in my view, stem from one's general theory of metaphysical explanation and will substantially differ between different argument views. For example, DN theorists will think that the argument from $A_{1} \ldots A_{n}$ to $B$ is explanatory because $A_{1} \ldots A_{n}$ non-redundantly entail $B$ and at least one of $A_{1} \ldots A_{n}$ is a metaphysical law, whereas unificationists might want to say that the argument in question is explanatory because it is part of the best systematization.

40 See Dasgupta 2014a and Schaffer 2017a. Strictly speaking, Dasgupta defends a view on which grounding facts are grounded in some other facts (on his favored view, facts about essence), but these facts in turn are not apt to be grounded. The label 'Trialism' originates from deRosset 2013.
} 
arbitrary iteration of grounding. ${ }^{41}$ By taking explanations to be arguments, both aspects of my approach can be independently motivated. For one, if explanations are arguments then there are syntactic constraints on the sorts of questions we can legitimately ask about them, which naturally leads to Trialism. For another, there is a plausible connection between an explanatory argument and the fact that it exists: intuitively, the premises of the former explain the latter, thereby leading to a close cousin of the Straightforward Account not about metaphysical explanation but about facts about metaphysically explanatory arguments.

The second component of the account I sketched above raises the question of whether the view inherits a problem from the Straightforward Account, initially raised by Shamik Dasgupta. Dasgupta complains that the Straightforward Account implies that facts that should intuitively "get different explanations get the same explanation" (2014b: 573). For example, $\mathrm{P}<_{\mathrm{e}} \mathrm{PvP}$ and $\mathrm{P}<{ }_{\mathrm{e}} \sim \mathrm{P}$ would both be explained by P; yet one might feel that some fact about how disjunction works should figure in the explanation of the first fact and some fact about how negation works should figure in the explanation of the second. There is an analogous objection to my proposed explanation of the existence of the corresponding explanatory arguments: they both appear to be explained by P, which makes no mention of disjunction or negation. Moreover, one might think that the proper lesson to draw from this is that we shouldn't think of the explanatory analogue of Carroll's regress as vicious: perhaps the logical connection between $\mathrm{P}$ and $\mathrm{PvP}$ (and also the way this logical connection ensures, along with $\mathrm{P}$, that $\mathrm{PvP}$ —and so on) does figure among PvP's explanantia even if it doesn't have to be added as a premise to make the argument from $\mathrm{P}$ to PvP valid. ${ }^{42}$

In response, we should first note that there are two separate ideas behind Dasgupta's objection. One is that if a fact to be explained involves a certain kind of structure (for example: it is itself an

\footnotetext{
41 The Straighforward Account has been defended by Bennett (2011) and deRosset (2013).

42 Thanks to an anonymous referee for drawing my attention to this complication.
} 
explanation fact with a disjunctive explanandum), its explanans has to say something about that structure (in the case at hand, about disjunction). Call this the Structural Requirement. A second idea is that if two facts about metaphysical explanation are different, there has to be a difference between their explanantia that accounts for this difference. So, the second part of Dasgupta's complaint has to do with an unexplained contrast: the explanantia of $\mathrm{P}<_{\mathrm{e}} \mathrm{PvP}$ and of $\mathrm{P}<_{\mathrm{e}} \sim \sim \mathrm{P}$ (or of the existence of the corresponding explanatory arguments - a qualification I will omit in the next few paragraphs, for better readability) should account for the difference between $\mathrm{P}<_{\mathrm{e}} \mathrm{PvP}$ and $\mathrm{P}<_{\mathrm{e}}$ $\sim \sim$ P, which is something that simply citing P doesn't deliver. Call this the Contrastive Requirement.

These two aspects are worth distinguishing because deRosset (2013: 20-21) addresses (in my view convincingly) a complaint similar to Dasgupta's, but when doing so he's mostly focusing on the Structural Requirement. However, I think his answer can be shown also to addresses the Contrastive Requirement. His first point is that if there is a problem here, it's not specific to metaphysical explanation facts. For example, if the explanation of $\mathrm{P}<{ }_{\mathrm{e}} \mathrm{PvP}$ should indeed mention disjunction, why shouldn't the explanation of $\mathrm{PvP}$ as well? But if it should, we need to revise a lot more than the answer to the Question of Explaining Explanation I offered above. We would need to abandon any grounding claim according to which some lower-level facts ground some higher-level fact such that the grounds make no mention of the higher-level facts. I take it that this consequence is sufficiently implausible to cast doubt on the Structural Requirement. But note that a similar reasoning is equally effective against the Contrastive Requirement. If $\mathrm{P}<_{\mathrm{e}} \mathrm{PvP}$ and $\mathrm{P}<_{\mathrm{e}} \sim \sim \mathrm{P}$ should have different explanantia, then it would seem that so should PvP and $\sim$ P. After all, merely citing P doesn't explain the difference between $\operatorname{PvP}$ and $\sim \sim \mathrm{P}$, either. More generally: the Contrastive Requirement threatens to yield a generic ban on "grounding forks", i.e. facts that ground at least two facts, neither of which is a partial ground of the other. Yet grounding forks seem ubiquitous. The fact that Socrates exists grounds both the fact that \{Socrates\} exists and the fact that some philosopher 
exists. But neither of the latter two facts is a partial ground of the other, and their ground doesn't involve anything that would account for the difference between set formation and existential quantification.

Second, deRosset also identifies an intuition that plausibly motivates the Structural Requirement: that the total explanatory story we need to tell to explain $\mathrm{P}<_{\mathrm{e}} \mathrm{PvP}$ needs to mention disjunction somewhere, and that the complete explanatory story we need to tell to explain $\mathrm{P}<{ }_{\mathrm{e}} \sim \mathrm{P}$ needs to mention negation somewhere. However, as he points out this doesn't mean that disjunction and negation need to be mentioned by the respective explanantia. This observation, too, can serve double duty in resisting the Contrastive Requirement. $\mathrm{P}<_{\mathrm{e}} \mathrm{PvP}$ and $\mathrm{P}<_{\mathrm{e}} \sim \sim \mathrm{P}$ differ in the explanatory stories we need to tell to get them: the first uses disjunction introduction whereas the second uses negation introduction. Still, these inference rules don't need to be mentioned among the explanantia of these facts. Similarly, the total explanatory story we need to tell to get an argument to the effect that there is an explanatory argument from $\mathrm{P}$ to $\mathrm{PvP}$ will differ from the total explanatory story we need to tell to get an argument to the effect that that there is an explanatory argument from $\mathrm{P}$ to $\sim \mathrm{P}$. But this is something we can accept without endorsing the Contrastive Requirement, since it doesn't follow that disjunction and negation need to be mentioned in the explanantia themselves.

It's worth adding that when we reject the Contrastive Requirement we don't thereby reject the demand for an explanation of the difference between the explanatory argument from P to PvP and the explanatory argument from $\mathrm{P}$ to $\sim \sim \mathrm{P}$. It's just that the explanation of why these arguments differ doesn't have to be the same as the explanation of why either argument exists. Instead, it can be something entirely banal; for example, perhaps the explanatory argument from $\mathrm{P}$ to $\mathrm{PvP}$ is different from the explanatory argument from $\mathrm{P}$ to $\sim \sim \mathrm{P}$ simply because they have different conclusions, and if two arguments have different conclusions they cannot be identical. 
In the foregoing paragraphs I didn't intend to show beyond doubt that facts about the connection between an explanatory argument's premises and its conclusion must not be counted among the explanantia of why that explanatory argument exists. After all, Carroll's puzzle shows that inference rules don't need to be added as premises to make an argument valid, but it doesn't automatically follow that they can't serve as explanantia. My point is, rather, that we don't need to count them as such; there is a perfectly acceptable alternative that gives justice to the intuition behind both the Structural Requirement and the Contrastive Requirement without ultimately caving in to them. But if you still think that the explanans of why such and such explanatory argument exists should mention the inference rules used in the argument (or corresponding logical laws, or some such), I'm happy to leave open this possibility as a fallback option. My main purpose was only to show that one way or other, e-theorists who identify metaphysical explanations with arguments have the resources to partly deflect and partly answer the Question of Explaining Explanation.

To be sure, I didn't consider all possible views in logical space that reject the Backing Model, so it would be too strong to conclude that the Question of Explaining Explanation doesn't arise if we reject this model. But pattern subsumption views, along with the idea that a metaphysical explanation is a particular type of argument, provide a natural alternative to the Backing Model. Moreover, this alternative is arguably the most popular one among e-theorists and has well worked out analogues in the scientific explanation literature. For this reason, even the limited conclusion that argument theorists of explanation can address (and to some extent deflect) the Question of Explaining Explanation is of great significance.

\section{The Question of Producing Explanation}

The Question of Explaining Explanation arises for everyone; it's another matter that most grounding theorists are in a good position to easily answer or even dismiss it, without having to 
recourse to the kinds of considerations that usually go into answering the question. By contrast, the Question of Producing Explanation (as well as the other two disambiguations of QIG I will consider later) only arises for p-theorists. However, we can now use some of the easy answers to the Question of Explaining Explanation to generate similarly straightforward answers to the Question of Producing Explanation. I will go by the same distinction I relied on in the previous section: either the production facts fully explain the metaphysical explanation facts or they need to be supplemented with ancillary conditions.

\subsection{Simple Productionism and the Question of Producing Explanation}

In section 4.2, I introduced Simple Productionism as the view that the production facts fully explain the metaphysical explanation facts:

$$
\begin{aligned}
& \text { Simple Productionism about Explaining Explanation } \\
& \square\left(\left(A_{1} \ldots A_{n}<{ }_{e} B\right) \rightarrow\left(\left(A_{1} \ldots A_{n}<{ }_{p} B\right)<_{e}\left(A_{1} \ldots A_{n}<{ }_{e} B\right)\right)\right)
\end{aligned}
$$

We can quickly verify that this view immediately settles what produces the metaphysical explanation facts. Take some fact about metaphysical explanation, $A_{1} \ldots A_{n}<_{e} B$. According to above the principle, this fact is metaphysically explained by $A_{1} \ldots A_{n}<_{p} B$. But what explains the higher-order metaphysical explanation fact $\left(A_{1} \ldots A_{n}<{ }_{p} B\right)<_{e}\left(A_{1} \ldots A_{n}<{ }_{e} B\right)$ ? Since Simple Productionism is a general thesis, it should be true of any fact about metaphysical explanation, including the higherorder fact at issue. This gives us

$$
\left(\left(A_{1} \ldots A_{n}<_{p} B\right)<_{p}\left(A_{1} \ldots A_{n}<{ }_{e} B\right)\right)<_{e}\left(\left(A_{1} \ldots A_{n}<{ }_{p} B\right)<_{e}\left(A_{1} \ldots A_{n}<e\right)\right)
$$


But if this sentence is true, its explanans clause is true as well. And its explanans clause explicitly specifies that what produces $A_{1} \ldots A_{n}<{ }_{e} B$ is $A_{1} \ldots A_{n}<_{p} B$. Since I didn't rely on any particular feature of $A_{1} \ldots A_{n}$ and $B$ in the above this reasoning (for example, I didn't assume that they have no further explanatory structure), we can infer the following general principle:

$$
\begin{aligned}
& \text { Simple Productionism about Producing Explanation } \\
& \square\left(\left(A_{1} \ldots A_{n}<{ }_{e} B\right) \rightarrow\left(\left(A_{1} \ldots A_{n}<{ }_{p} B\right)<_{p}\left(A_{1} \ldots A_{n}<{ }_{e} B\right)\right)\right)
\end{aligned}
$$

Thus a metaphysical explanation fact's producer is the same fact as the one that metaphysically explains that metaphysical explanation fact. This answers the Question of Producing Explanation for adherents of a simple version of the Backing Model. It's essentially the same answer as the one we ended up with to the Question of Explanation Explanation. Namely: the metaphysical explanation facts are not only metaphysically explained but also produced by the production facts.

\subsection{Ancillary Productionism and the Question of Producing Explanation}

In section 4.2 I distinguished two kinds of answers to the Question of Explaining Explanation that appeal to ancillary conditions besides production. The first one was

Naïve Ancillary Productionism about Explaining Explanation

$$
\square\left(\left(A_{1} \ldots A_{n}, C_{1} \ldots C_{k}<e\right) \rightarrow\left(\left(A_{1} \ldots A_{n}, C_{1} \ldots C_{k}<{ }_{p} B\right)<{ }_{e}\left(A_{1} \ldots A_{n}, C_{1} \ldots C_{k}<{ }_{e} B\right)\right)\right)
$$

I argued against this view on the basis that it objectionably treats ancillary conditions as producers themselves, which goes against the whole rationale of giving these conditions a special status. In its place, I offered a more complicated account, Sophisticated Ancillary Productionism about 
Explaining Explanation, which systematically assigns the ancillary conditions to an explanatory role different from that of the production base: it says that as a matter of necessity, whenever $A_{1} \ldots A_{n}$, $C_{1} \ldots C_{k}<{ }_{e} B$, it's also the case that $\left(A_{1} \ldots A_{n}<{ }_{p} B, C_{1}^{\prime} \ldots C_{m}^{\prime}\right)<_{e}\left(A_{1} \ldots A_{n}, C_{1} \ldots C_{k}<{ }_{e} B\right)$.

If we take a closer look at this formulation, we can easily see that it already implicitly answers the Question of Producing Explanation. For something counts as an ancillary condition in an explanation just in case it's part of the explanans base but not of the production base. So, we can get the production base of any explanation by removing all the ancillary conditions from its explanans base. This gets us the following principle:

$$
\begin{aligned}
& \text { Sophisticated Ancillary Productionism about Producing Explanation } \\
& \square\left(\left(\mathrm{A}_{1} \ldots \mathrm{A}_{\mathrm{n}}, \mathrm{C}_{1} \ldots \mathrm{C}_{\mathrm{k}}<\mathrm{e}\right) \rightarrow\left(\left(\mathrm{A}_{1} \ldots \mathrm{A}_{\mathrm{n}}<_{\mathrm{p}} \mathrm{B}\right)<_{\mathrm{p}}\left(\mathrm{A}_{1} \ldots \mathrm{A}_{\mathrm{n}}, \mathrm{C}_{1} \ldots \mathrm{C}_{\mathrm{k}}<\mathrm{e}\right)\right)\right)
\end{aligned}
$$

We can now see that while Sophisticated Ancillary Productionism and Simple Productionism give different answers to the Question of Explaining Explanation, they basically agree on the Question of Producing Explanation: on both views, the full producer of a metaphysical explanation fact $\mathrm{E}$ is a fact to the effect that E's production base produces E's explanandum. On reflection, this shouldn't be surprising. Simple and Ancillary Productionism offer different accounts of metaphysical explanation in so far as the latter, but not the former, assigns a significant role to ancillary conditions. But they don't differ in their treatment of production itself. It's just that according to Ancillary Productionism, there is more to metaphysical explanation than production. 


\section{The Question of Producing Production}

What produces the production facts? Unlike in the previous cases, we cannot get my proposed interpretations of the Backing Model to mechanically spit out an answer to this question. We could squeeze out such an answer if the following principle were true:

$$
\text { (Dubious) } \square\left(\left(\mathrm{X}_{1} \ldots \mathrm{X}_{\mathrm{m}}<\mathrm{e}\left(\mathrm{A}_{1} \ldots \mathrm{A}_{\mathrm{n}}<\mathrm{e} \mathrm{B}\right)\right) \rightarrow\left(\mathrm{X}_{1} \ldots \mathrm{X}_{\mathrm{m}}<{ }_{\mathrm{e}}\left(\mathrm{A}_{1} \ldots \mathrm{A}_{\mathrm{n}}<\mathrm{p}\right)\right)\right)
$$

But it's not clear why we should believe that. The Backing Model (on either of the two interpretations I offered) allows us to draw inferences from the metaphysical explanation facts to the production facts, or more accurately, from sentences whose main connective is $<_{\mathrm{e}}$ to sentences whose main connective is $<_{\mathrm{p}}$. It is this feature I exploited when I offered "easy" answers to the Question of Explaining Explanation and the Question of Producing Explanation in sections 4 and 5. But to get Dubious, we would also need to infer from a sentence whose main connective is $<_{\mathrm{e}}$ another sentence whose main connective is $<_{\mathrm{e}}$, albeit with a different explanandum clause. There is nothing in the Backing Model as such to automatically license such a move.

I'm inclined to think that the Question of Producing Production is where the energy spent on answering QIG could be most fruitfully directed, since I have no "easy" answer to offer to this question. However, this doesn't mean that the preceding discussion has no bearing on it. This is because the plausibility of some of the arguments that have been offered in defense of one answer or other to QIG crucially depends on which interpretation of QIG we are focusing on. Without defending any first-order view in detail, let me demonstrate this point through one example.

Some are attracted to a kind of Trialism about production: the production facts are inapt to be produced because they are the wrong sorts of things to be produced. Dasgupta (2014b) defended a close cousin of this view: the grounding facts are grounded by facts about essence, which are in turn 
the wrong kinds of things to be grounded. Most of the details of Dasgupta's view need not concern us here; what I want to emphasize is that he motivates it through an analogy with causation. Facts about pure arithmetic, he notes, are not apt to be caused; likewise, the grounding facts (or perhaps the facts that ground the grounding facts) are not apt to be grounded. This argument received a substantial amount of criticism, most of which has been directed at Dasgupta's analogy between causation and grounding. ${ }^{43}$

I don't intend to weigh in on the debate between Dasgupta and his opponents here. I only wish to make one point: Dasgupta's argument doesn't even get off the ground if interpreted as an argument for Trialism about the Question of Explaining Explanation. Whether causation is analogous to grounding qua production is a matter of dispute, which should be adjudicated on the basis of a careful comparison of the logical and structural features of the two relations. But inferring the features of metaphysical explanation from the features of causation is just a mistake; it relies on a conflation of causation with causal explanation (or, if you like, production with metaphysical explanation). So, while Dasgupta's argument from causal analogy might be defensible when understood as an argument for Trialism about production, it is a non-starter when interpreted as an argument for Trialism about metaphysical explanation. ${ }^{44}$ As we have seen, Trialism about metaphysical explanation is clearly false if some version of the Backing Model is true, while it is true on argument views of explanation, but for reasons that have nothing to do with considerations about causation.

\footnotetext{
43 See deRosset 2013, Glazier 2017, and Sider forthcoming. For general criticisms of the grounding-causation analogy, see Koslicki 2016 and Bernstein 2016.

${ }^{44}$ As a matter of fact, Dasgupta himself means metaphysical explanation by 'grounding'. So, his argument supports his own version of Trialism less well than a p-theoretic reinterpretation of it.
} 
Now, it may well turn out that Trialism is implausible even when understood as a thesis about production — as I said, I have no interest in settling the issue here. I mentioned this example merely for illustrative purposes: the various moves and counter-moves in the fast-growing literature on iterated grounding cannot be evaluated without first getting clear on which disambiguation of QIG is at issue. As I earlier argued, most theorists can give "easy" answers to the Question of Explaining Explanation and consequently also to the Question of Explaining Production. By contrast, I suspect that the Question of Producing Production is a substantive question that is not settled by the foregoing considerations. However, "not settled" doesn't mean "not affected": potentially forceful arguments for answers to the Question of Producing Production may be entirely misguided when reframed as arguments for analogous answers to the Question of Explaining Explanation. Dasgupta's argument from causal analogy for Trialism is one case in point; there may well be others.

\section{The Question of Explaining Production}

In the previous section I argued that the considerations that led to "easy answers" to the Question of Explaining Explanation and the Question of Producing Explanation didn't license a similarly deflationary approach to the Question of Producing Production. As far as I can see, it is this question that should be in the forefront of future research on QIG.

While the answer to the Question of Producing Production is far from obvious, the answer to the Question of Explaining Production is trivial given any particular answer to the Question of Production. There are three possibilities. One is that the production facts are not produced (perhaps because they are inapt to be produced). In this case, given the Backing Model, they are also not explained. To be clear, it is not at all obvious that a fact can be metaphysically explained only if it's produced; in section 4.3 I discussed an important group of views that deny this. What is obvious is that if the Backing Model is true then metaphysical explanation requires production, in which case the 
production facts cannot be explained unless they are produced. A second possibility is that whichever facts, $\mathrm{X}_{1} \ldots \mathrm{X}_{\mathrm{n}}$, explain the production facts, ancillary conditions are not among them. In that case, the explanans base of the production facts is simply their production base; therefore, it's simply $\mathrm{X}_{1} \ldots \mathrm{X}_{\mathrm{n}}$ that explain the production facts. And a third possibility is that the producers of the production facts metaphysically explain those facts only together with some ancillary conditions. In that case, it's the producers $\mathrm{X}_{1} \ldots \mathrm{X}_{\mathrm{n}}$ and the ancillary conditions together that metaphysically explain the production facts.

Of course, the hard part is figuring out what $\mathrm{X}_{1} \ldots \mathrm{X}_{\mathrm{n}}$ are, a question I said nothing about in the previous section. What is clear is that whatever they are, once we specified them there is no further barrier to answering the Question of Explaining Production. This reinforces the suspicion that it's the Question of Producing Production that should have been the main focus of the iterated grounding literature from the get-go.

\section{Concluding remarks}

QIG has generated a great amount of discussion, but most of it has proceeded in isolation from a number of foundational questions concerning grounding. Most important of these are the relation between grounding and metaphysical explanation and the role (or lack thereof) of ancillary conditions in the latter. I have argued that once we draw the relevant distinctions, we are faced with no fewer than four questions of iterated grounding. I have also argued that given some plausible interpretative assumptions about what it would mean for grounding (or any other relations, collectively: "production") to back metaphysical explanation, several salient views about grounding automatically imply "easy" answers to at least some of these questions. To make my main findings easier to understand, I summarized them in a chart below. 


\begin{tabular}{|c|c|c|c|c|c|}
\hline & & $\begin{array}{l}\text { What } \\
\text { metaphysically } \\
\text { explains the } \\
\text { metaphysical } \\
\text { explanation facts? }\end{array}$ & $\begin{array}{l}\text { What } \\
\text { produces the } \\
\text { metaphysical } \\
\text { explanation } \\
\text { facts? }\end{array}$ & $\begin{array}{l}\text { What } \\
\text { produces the } \\
\text { production } \\
\text { facts? }\end{array}$ & $\begin{array}{l}\text { What } \\
\text { metaphysically } \\
\text { explains the } \\
\text { production facts? }\end{array}$ \\
\hline \multirow[t]{2}{*}{$\begin{array}{l}\text { Backing } \\
\text { Model }\end{array}$} & $\begin{array}{l}\text { Simple } \\
\text { Productionism }\end{array}$ & Production Facts & $\begin{array}{l}\text { Production } \\
\text { Facts }\end{array}$ & $\begin{array}{l}\mathrm{X} \text { (where it's a } \\
\text { substantive } \\
\text { issue what } \mathrm{X} \text { is) }\end{array}$ & $\mathrm{X}$ \\
\hline & $\begin{array}{l}\text { Sophisticated } \\
\text { Ancillary } \\
\text { Productionism }\end{array}$ & $\begin{array}{l}\text { Production Facts }+ \\
\text { ancillary conditions }\end{array}$ & $\begin{array}{l}\text { Production } \\
\text { Facts }\end{array}$ & $\mathrm{X}$ & $\begin{array}{l}\mathrm{X}+\text { ancillary } \\
\text { conditions }\end{array}$ \\
\hline \multirow[t]{2}{*}{$\begin{array}{l}\text { Non- } \\
\text { backing } \\
\text { views }\end{array}$} & $\begin{array}{l}\text { Argument } \\
\text { Views }\end{array}$ & $\begin{array}{l}\text { N/A (but: a sentence } \\
\text { that asserts the } \\
\text { existence of a sound } \\
\text { explanatory } \\
\text { argument is } \\
\text { explained by that } \\
\text { argument's premises) }\end{array}$ & $\mathrm{N} / \mathrm{A}$ & $\mathrm{N} / \mathrm{A}$ & $\mathrm{N} / \mathrm{A}$ \\
\hline & $\begin{array}{l}\text { Other non- } \\
\text { backing views }\end{array}$ & $?$ & $\mathrm{~N} / \mathrm{A}$ & $\mathrm{N} / \mathrm{A}$ & $\mathrm{N} / \mathrm{A}$ \\
\hline
\end{tabular}

These findings are significant, but one shouldn't draw hasty conclusions from them. I have argued only that we can often get an automatic answer to the relevant interpretation of QIG. This doesn't necessarily mean that we need to reject some other answers that have been given in the literature. For example, Litland (2017) defends a novel answer to QIG that appeals to the notions of zerogrounding and non-factive grounding, but which, he argues, is fully consistent with Bennett's and deRosset's Straightforward Account; it's just that in an important sense, it gives a deeper and more informative answer. Similarly, in those cases where I defended an "easy" answer to a disambiguation of QIG, nothing rules out alternative answers that might also correctly answer the respective disambiguation. (Of course, things are different in cases where I argued that we should reject the relevant question as illegitimate; this does rule out views that attempt to give a substantive answer.)

Still, I think we can draw a number of important conclusions. First, it's surprising that most grounding theorists can answer at least some versions of QIG so easily, and that they can do so 
independently of the sorts of considerations that usually go into answering the question. Second, many of the easy answers are incompatible with popular constraints on acceptable answers to QIG. Most obviously, since all forms of productionism explain the metaphysical explanation facts in terms of production facts that feature some non-fundamental (because produced) facts, these views violate Purity as well as Dasgupta's level-connecting constraint. Whether this is a reason to reject the constraints or the Backing Model itself is a substantive question I cannot settle here, but something has to give. Third, if nothing else, my discussion shows that how we specify the connection between grounding and metaphysical explanation heavily bears on QIG. We cannot fruitfully discuss what grounds the grounding facts without first addressing the difficult issue of what grounding is and how it's related to metaphysical explanation. ${ }^{45}$

\section{References}

Audi, Paul (2012a), "Grounding: Toward a theory of the in-virtue-of relation," Journal of Philosophy, 109: 685-711

Audi, Paul (2012b), "A Clarification and Defense of the Notion of Grounding," in Fabrice Correia and Benjamin Schnieder (eds.), Metaphysical Grounding, Cambridge: Cambridge University Press

Bennett, Karen (2011), Construction area (no hard hat required), Philosophical Studies, 154: 79-104

Bennett, Karen (2017), Making Things Up, Oxford: Oxford University Press

Bernstein, Sara (2016), "Grounding is Not Causation,” Philosophical Issues, 30: 21-38

Brody, Baruch (1972), “Towards an Aristotelean Theory of Scientific Explanation," Philosophy of Science, 39: 20-31

Carnino, Pablo (2017), “Grounding Is Not Superinternal,” Thought, 6: 24-32

Chalmers, David and Frank Jackson (2001), "Conceptual analysis and reductive explanation," Philosophical Review, 110: 315-61

\footnotetext{
45 For helpful comments and discussion I'm grateful to Scotty Dixon, Jon Litland, Jonathan Shaheen, Naomi Thompson, Alastair Wilson, an anonymous referee of this journal, and audiences at a workshop entitled "Metaphysical Explanation II-Unionism and Separatism" at the University of Gothenburg and at department colloquia at the Hebrew University of Jerusalem and the University of Vienna.
} 
Correia, Fabrice (2013), "Metaphysical Grounds and Essence," in M. Hoeltje, B. Schnieder, A. Steinberg (eds.), Varieties of Dependence, Philosophia Verlag

Dasgupta, Shamik (2014a), “On the plurality of grounds,” Philosophers' Imprint, 14 (20): 1-28

Dasgupta, Shamik (2014b), “The possibility of physicalism,” Journal of Philosophy, 111: 557-592

Dasgupta, Shamik (2017), "Constitutive Explanation,” Philosophical Issues, 27: 74-97

deRosset, Louis (2013), “Grounding Explanations,” Philosophers' Imprint, 13 (7): 1-26

deRosset, Louis (ms), Fundamental Things, under contract at Oxford University Press

Dixon, T. Scott (2016), "What is The Well-Foundedness of Grounding?,” Mind, 125: 439-68

Ehring, Douglas (2011), Tropes: Properties, Objects, and Mental Causation, Oxford University Press

Fine, Kit (2001), “The Question of Realism,” Philosophers' Imprint, 1 (2): 1-30

Fine, Kit (2012), "Guide to Ground," in Correia and Schnieder

Friedman, Michael (1974), "Explanation and Scientific Understanding," Journal of Philosophy, 71: 5-19

Glazier, Martin (2017), “Essentialist Explantion,” Philosophical Studies, 174: 2871-89

Glazier, Martin (forthcoming), "Ground and Explanation," in Michael J. Raven (ed.), The Routledge Handbook of Metaphysical Grounding

Hempel, Carl G. and P. Oppenheim (1948), "Studies in the Logic of Explanation," Philosophy of Science, 15: 135-175

Hempel, Carl G. (1965), Aspects of Scientific Explanation, New York: The Free Press

Kim, Jaegwon (1994), "Explanatory Knowledge and Metaphysical Dependence," Philosophical Issues, 5: 51-69

Kitcher, Philip (1989), "Explanatory Unification and the Causal Structure of the World," in Philip Kitcher \& Wesley Salmon (eds.), Scientific Explanation, Minneapolis: University of Minnesota Press

Kment, Boris (2014), Modality and Explanatory Reasoning, Oxford University Press

Koslicki, Kathrin (2016), "Where Grounding and Causation Part Ways: Comments on Jonathan Schaffer," Philosophical Studies, 173: 49-100

Kovacs, David Mark (2017), "Grounding and the argument from explanatoriness," Philosophical Studies, 174: 2927-2952

Kovacs, David Mark (forthcoming-1), “The myth of the myth of supervenience," Philosophical Studies

Kovacs, David Mark (forthcoming-2), "Metaphysically explanatory unification,” Philosophical Studies

Leuenberger, Stephan (2014), “Grounding and Necessity,” Inquiry, 57: 151-174

Litland, Jon (2015), "Grounding, Explanation, and the Limit of Internality,” Philosophical Review: 124: $481-532$

Litland, Jon (2017), "Grounding ground”, Oxford Studies in Metaphysics, 10: 279-316

Loss, Roberto (2016), "Grounds, Roots and Abysses," Thought, 4: 41-52 
Maurin, Sofia (forthcoming), "Grounding and Metaphysical Explanation: it's complicated," Philosophical Studies

McCarthy, Timothy (1977), "On an Aristotelian Model of Scientific Explanation," Philosophy of Science, 44: 159-166

Miller, Kristie \& James Norton (2017), “Grounding: it's (probably) all in the head,” Philosophical Studies, 174: 3059-81

Miller, Kristie \& James Norton (forthcoming), “A Psychologistic Account of Metaphysical Explanation," Synthese

Rabin, Gabriel Oak and Brian Rabern (2016), "Well Founding Grounding Grounding," Journal of Philosophical Logic, 45: 349-379

Railton, Peter (1981), "Probability, explanation, and information," Synthese, 48: 233-256

Raven, Michael (2012), “In Defence of Ground,” Australasian Journal of Philosophy, 90: 687-701

Raven, Michael (2015), “Ground,” Philosophy Compass, 10: 322-333

Rodriguez-Pereyra (2005), "Why Truthmakers," Helen Beebee and Julian Dodd (eds.), Truthmakers: The Contemporary Debate, Oxford University Press, pp. 17-31

Rosen, Gideon (2006), "The limits of contingency," in Fraser MacBride (ed.), Identity and Modality, Oxford University Press, pp. 13-39

Rosen, Gideon (2010), "Metaphysical dependence: grounding and reduction," in Bob Hale and Aviv Hoffman (eds.), Modality: Metaphysics, Logic, and Epistemology, Oxford: Oxford University Press

Ruben, David-Hillel (1990), Explaining Explanation, London: Routledge

Schaffer, Jonathan (2009), "On what grounds what," in Chalmers et al

Schaffer, Jonathan (2016), "Grounding in the Image of Causation," Philosophical Studies, 173: 49-100

Schaffer, Jonathan (2017a), “The Ground Between the Gaps,” Philosophers' Imprint, 17: 1-21

Schaffer, Jonathan (2017b), "Laws for Metaphysical Explanation," Philosophical Issues, 27: 302-321

Schnieder, Benjamin (2010), “A Puzzle About 'Because',' Logique et Analyse, 53: 317-343

Shaheen, Jonathan (2016) "The causal metaphor account of metaphysical explanation," Philosophical Studies, 174: 553-78

Shumener, Erica (2017), “The Metaphysics of Identity,” Philosophy Compass, 12(1): e12397

Sider, Theodore (2011), Writing the Book of the World, Oxford: Oxford University Press

Sider, Theodore (forthcoming), "Ground grounded," Philosophical Studies

Skiles, Alexander (2015), “Against Grounding Necessitarianism,” Erkenntnis, 80: 717-51

Skow, Bradford (2016), Reasons Why, Oxford: Oxford University Press

Strevens, Michael (2008), Depth: An Account of Scientific Explanation, Cambridge, MA: Harvard University Press

Taylor, Elanor (2018), “Against Explanatory Realism,” Philosophical Studies, 175: 197-219 
Thompson, Naomi (2016), "Grounding and Metaphysical Explanation," Proceedings of the Aristotelian Society, 116: 395-402

Trogdon, Kelly (2013), “Grounding: Necessary or Contingent?," Pacific Philosophical Quarterly, 94: 465-85

Trogdon, Kelly (2018), “Grounding-Mechanical Explanation,” Philosophical Studies, 175: 1289-1309

van Inwagen, Peter (2012), "Causation and the Mental," in Kelly James Clark and Michael Rea (eds.), Reason, Metaphysics, and Mind, Oxford: Oxford University Press, pp. 153-170

White, Morton (1965), The Foundations of Historical Knowledge, Harper \& Row

Wilsch, Tobias (2016), "The Deductive-Nomological Account of Metaphysical Explanation," Australasian Journal of Philosophy, 94: 1-23

Wilson, Alastair (2018), "Metaphysical causation,” Nous, 723-751

Wilson, Jessica M. (1999), "How superduper does a physicalist supervenience need to be?," Philosophical Quarterly, 50: 33-52

Wilson, Jessica M. (2014), “No Work for a Theory of Grounding,” Inquiry, 57: 1-45

Wilson, Jessica M. (2018), “Grounding-Based Formulations of Physicalism,” Topoi, 34: 495-512 